\title{
Penerapan Model Pembelajaran Relating, Experiencing, Applying, Cooperating, Transferring (REACT) untuk Meningkatkan Pemahaman Konsep Fisika SMA
}

\author{
M.I. Sugita*, Y.R. Liana, A.F. Lestari, A. Rosilawati, B. Subali \\ Program Studi Pendidikan Fisika, Program Pascasarjana UNNES, Indonesia \\ *Email: iqbalsugita1995@gmail.com
}

Received: July 20th, 2020. Accepted: August 16 $6^{\text {th }}$ 2020. Published: August 31 $1^{\text {st }}, 2020$

\begin{abstract}
Abstrak
Tujuan penelitian ini adalah untuk menguji efektivitas model pembelajaran Relating, Experiencing, Applying, Cooperating, Transferring (REACT) dalam meningkatkan pemahaman konsep fisika siswa. Penelitian ini menggunakan metode Penelitian Tindakan Kelas (PTK) dengan subjek penelitian siswa kelas $X$ MIPA 4 SMA N 2 Batang. Teknik pengumpulan data menggunakan tes. Hasil penelitian siklus I menunjukkan jumlah siswa yang mendapatkan nilai $\geq 60$ sebanyak 4 siswa dan siklus II sebanyak 14 siswa. Hasil tersebut menunjukan bahwa model pembelajaran REACT dapat meningkatkan pemahaman konsep fisika siswa. Proses pembelajaran yang dilakukan selalu dihubungkan dengan peristiwa-peristiwa yang terjadi di kehidupan nyata sehingga siswa lebih memahami konsep secara mendalam. Model pembelajaran REACT dapat diterapkan pada materi fisika yang lain agar siswa lebih terlibat aktif dalam pembelajaran dan meningkatkan pemahaman konsep fisika siswa.
\end{abstract}

\begin{abstract}
The aims of this study was to test the effectiveness of the Relating, Experiencing, Applying, Cooperating, Transferring (REACT) learning model in improving students' understanding of physics concepts. This research used Action Research with the research subjects of class X MIPA 4 SMA N 2 Batang. Data collection techniques using tests. The results of the research in cycle I showed the number of students who got a score of $\geq 60$
\end{abstract}


was 4 students and cycle II was 14 students. These results indicate that the REACT learning model can improve students' understanding of physics concepts. The learning process that is carried out is always connected with events that occur in real life so that students understand the concept more deeply. The REACT learning model can be applied to other physics materials so that students are more actively involved in learning and improve students' understanding of physics concepts. (C)2020PERJ

Keywords: Action Research; the understanding of physics concepts; REACT.

\section{PENDAHULUAN}

Pendidikan diartikan sebagai suatu usaha nyata dan terstruktur untuk melaksanakan proses belajar mengajar agar siswa dapat secara aktif mengembangkan, membangkitkan, dan mengeluarkan potensi ataupun kemampuan yang ada pada dirinya. Kemampuan yang diharapkan seperti: kekuatan spritual, kepribadian, kecerdasan, akhlak mulia, keagamaan, pengendalian diri maupun keterampilan yang diperlukan diri sendiri, masyarakat, bangsa, dan Negara. Depdiknas (2003) menyatakan bahwa pendidikan sebagai suatu proses maupun cara untuk mencapainya sebuah tujuan.

Pemahaman konsep mengacu pada pemahaman yang bersifat konstruktivistik, yaitu understanding construction lebih penting dari pada memorizing fact (Abdullah \& Shariff, 2008). Pemahaman merupakan suatu proses mental yang mengharuskan terjadinya adaptasi maupun transformasi ilmu pengetahuan (Gardber, 1999). Pemahaman dapat diukur dari hasil evaluasi pada diri sendiri (Wenning, 2006). Oleh karena itu, dalam mengemas pembelajaran, guru dianjurkan untuk lebih aktif meminta siswa melakukan kegiatan percobaan berupa eksperimen atau praktikum dan pada proses belajar mengajar tidak hanya berfokus pada how to teach tetapi lebih kepada orientasi berupa how to stimulate learning dan learning how to learn (Cunningham, 2005; Bryan, 2005; Gowin, 1985).

Berdasarkan hasil observasi di SMA N 2 Batang diperoleh informasi bahwa dalam melakukan kegiatan pembelajaran di kelas, guru masih menerapkan metode yang monoton atau klasik yaitu menggunakan sistem hafalan baik dari definisi, teori, dan persamaan fisika tanpa memaknai setiap definisi, teori, dan persamaan fisika yang disampaikan. Kegiatan pembelajaran semacam itu dapat mengakibatkan lemahnya penguasaan konsep siswa dan 
materi pelajaran fisika yang didapatkan mudah terlupakan. Salah satu tujuan dari pelajaran fisika yang tercantum pada kurikulum 2013 adalah penguasaaan terhadap konsep maupun prinsip serta memiliki keterampilan, kemampuan untuk dapat mengembangkan ilmu pengetahuan, serta mampu mengaplikasikan (Kemendikbud, 2013).

Salah satu cara untuk mengatasi masalah pemahaman konsep siswa yaitu dengan menerapkan suatu model pembelajaran yang menuntut siswa untuk berperan lebih aktif dan kreatif dalam kegiatan belajar mengajar. Peran guru hanya sebagai fasilitator yang mendorong siswa untuk lebih memaknai materi dan dapat mengkaitkan dengan kejadian yang ada di kehidupan sehari-hari (Fariyani, 2019). Model pembelajaran yang tepat dapat membantu tercapainya tujuan pembelajaran. Model pembelajaran sangat berpengaruh terhadap kemampuan siswa dalam menyerap materi (Effendi \& Pantriani, 2020).

Model pembelajaran yang diharapkan dapat mengatasi kurangnya penguasaan konsep siswa adalah model belajar Relating, Experiencing, Applying, Cooperating, Transferring (REACT) (Cahyono et al., 2017). Model pembelajaran REACT terdiri atas lima kegiatan utama, yaitu: 1) Relating, merupakan kegiatan pembelajaran yang menggabungkan materi yang sedang dipelajari dengan pengalaman maupun peristiwa kehidupan sehari-hari atau pengetahuan yang yang dimiliki sebelumnya; 2) Experiencing (mengalami), merupakan pembelajaran yang mengarahkan siswa belajar untuk melakukan suatu kegiatan (learning by doing) melalui tahapan eksplorasi, penemuan, pencarian, pemecahan masalah, aktivitas dan laboratorium; 3) Applying (menerapkan), adalah pembelajaran dengan menerapkan konsep yang telah dipelajari dan dipahami untuk memecahkan masalah yang realistik dan relevan; 4) Cooperating (bekerjasama), adalah pembelajaran yang menharuskan siswa agar bekerja sama, berkoloborasi, sharing, merespons, dan berkomunikasi dengan siswa yang lainnya; 5) Transferring (mentransfer), yaitu siswa diharapkan mampu menggunakan maupun mengaplikasikan sebuah pengetahuan yang dimiliki ke dalam konteks atau situasi yang baru (Cahyono et al., 2017).

Berdasarkan latar belakang tersebut, diperlukan penelitian tentang penerapan model pembelajaran Relating, Experiencing, Applying, Cooperating, Transferring (REACT) untuk meningkatkan pemahaman konsep fisika siswa SMA. Penelitian ini dilakukan untuk menganalisis peningkatan pemahaman konsep fisika siswa SMA N 2 Batang melalui penerapan model pembelajaran Relating, 
Experiencing, Applying, Cooperating, Transferring (REACT).

\section{METODE}

Penelitian ini menggunakan metode Penelitian Tindakan Kelas (PTK) dengan pendekatan kuantitatif. Teknik pengumpulan data menggunakan tes. Data yang telah didapatkan dianalisis secara persentase untuk melihat ketercapaian penguasaan konsep siswa. Subjek penelitian ini adalah 36 siswa kelas X MIPA 4 SMA N 2 Batang. Penelitian ini difokuskan untuk meningkatkan penguasaan konsep fisika siswa.

Langkah-langkah Penelitian Tindakan Kelas (PTK) meliputi perencanaan, implementasi, observasi, dan refleksi yang dilaksanakan secara beberapa siklus. Jumlah siklus disesuaikan dengan jumlah pertemuan yang dibutuhkan, yaitu dua siklus. Data penguasaan konsep siswa diperoleh berdasarkan hasil tes siswa yang diberikan di akhir pembelajaran yang kemudian dianalisis menggunakan Persamaan 1.

$$
\%=\frac{N}{\text { skor } \max } \times 100 \%
$$

\section{HASIL DAN PEMBAHASAN}

Data yang diperolah dianalisis untuk menentukan ketercapaian pemahaman konsep siswa. Selain itu, hasil ketercapaian konsep siswa juga dibandingkan dengan target yang telah ditetapkan. Hasil analisis ketercapaian penguasaan konsep siswa disajikan pada Tabel 1; dan hasil analisis perbandingan target ketercapaian penguasaan konsep siswa disajikan pada Tabel 2.

Tabel 1. Hasil Analisis Ketercapaian Penguasaan Konsep Siswa

\begin{tabular}{ccccc}
\hline Siklus & \multicolumn{4}{c}{ Interval Nilai } \\
\cline { 2 - 5 } & $86-100$ & $75-85$ & $60-74$ & $>60$ \\
\hline I & - & - & 4 siswa & 32 siswa \\
II & - & 4 siswa & 10 siswa & 22 siswa \\
\hline
\end{tabular}

Tabel 2. Perbandingan Target Ketercapaian Penguasaan Konsep Siswa

\begin{tabular}{ccccc}
\hline \multirow{2}{*}{ Perbandingan } & \multicolumn{2}{c}{ Persentase } & \multicolumn{2}{c}{ Jumlah Siswa } \\
\cline { 2 - 5 } & Target & Ketercapaian & Target & Ketercapaian \\
\hline Siklus I & $20 \%$ & $11.1 \%$ & 7 siswa & 4 siswa \\
Siklus II & $30 \%$ & $38.8 \%$ & 10 siswa & 14 siswa \\
\hline
\end{tabular}

Siklus I Penelitian Tindakan Kelas ini merupakan pertemuan pertama dengan materi gerak vertikal ke bawah dan gerak jatuh bebas. Proses pembelajaran awal yang berlangsung adalah guru memberikan deskripsi tentang kejadian-kejadian yang terjadi pada 
materi gerak vertikal ke bawah dan gerak jatuh bebas yang ditampilkan melalui bentuk video, animasi, gambar, dan demonstrasi (menjatuhkan bola tenis dari ketinggian tertentu).

Setelah diberikan gambaran awal terkait materi pembelajaran yang akan dibahas, guru mulai mengaitkan konsep dari gerak vertikal ke bawah dan gerak jatuh bebas dengan konsep gerak lurus berubah beraturan yang sudah diterima siswa pada pertemuan sebelumnya. Pada siklus I, guru menekankan konsep utama gerak yang arahnya vertikal ke bawah dan perbedaan antara gerak vertikal ke bawah dan gerak jatuh bebas. Penguatan terhadap penguasaan konsep yang baru siswa dapatkan dilakukan dengan menggunakan metode eksperimen. Siswa melakukan eksperimen secara berkelompok sesuai dengan panduan di LKS (Lembar Kerja Siswa) yang telah disiapkan atau diberikan oleh guru. Selama kegiatan eksperimen, guru sebagai fasilitator membimbing siswa ketika siswa mengalami kesulitan.

Hasil dari eksperimen yang telah dilakukan kemudian didiskusikan secara berkelompok untuk mendapatkan penguatan konsep dari materi gerak jatuh bebas dan gerak vertikal ke bawah. Hasil diskusi kelompok selanjutnya dipresentasikan di depan kelas. Pada kegiatan akhir atau penutup, guru bersama siswa merumuskan kesimpulan dari hasil diskusi maupun eksperimen secara menyeluruh.

Siklus II pada Penelitian Tindakan Kelas (PTK) ini merupakan pertemuan ke dua dengan materi gerak vertikal ke atas. Materi yang diajarkan pada pertemuan ini hanya satu pokok bahasan saja sehingga siswa lebih fokus dalam mengikuti pembelajaran. Berdasarkan hasil analisis data, pemahaman konsep siswa meningkat dari siklus I ke siklus II. Siswa lebih antusias dalam mengukuti pembelajaran karena sudah mulai terbiasa dengan pembelajaran aktif. Hal ini sesuai dengan hasil penelitian Ismaya, Subiki, \& Harijanto (2015) yang menyatakan bahwa pembelajaran fisika dengan menggunakan model Relating, Experiencing, Applying, Cooperating, dan Transfer (REACT) berdampak positif pada motivasi belajar siswa.

Model pembelajaran REACT berpengaruh secara signifikan terhadap keterampilan proses sains dan hasil belajar fisika siswa (Cahyono et al., 2017). Siswa dapat berdiskusi dan menyatakan pendapat selama pembelajaran berlangsung. Hal ini dapat melatih kemampuan komunikasi, baik secara verbal maupun tulisan. Selain itu, kemampuan matematis siswa juga terasah karena siswa dibiasakan untuk menyelesaikan permasalahan fisika yang memerlukan perhitungan matematis. Hasil penelitian Lailatul (2019) menyatakan hal serupa, 
bahwa strategi REACT pada masing-masing indikator meningkatan kemampuan berpikir penguasaan konsep. Ketercapaian kreatif dan komunikasi matematis pada indikator pemahaman konsep siswa memperoleh pembelajaran siklus I ditunjukkan pada Tabel 3 lebih baik.

Data penelitian juga dianalisis Tabel 4. untuk mengetahui ketercapaian

Tabel 3. Ketercapaian pada Indikator Penguasaan Konsep Siklus I

\begin{tabular}{lcccc}
\hline \multicolumn{1}{c}{$\begin{array}{c}\text { Indikator Penguasaan } \\
\text { Konsep }\end{array}$} & \multicolumn{3}{c}{ Interval Ketercapaian Skor } \\
\cline { 2 - 5 } $\begin{array}{l}\text { Menyatakan ulang sebuah } \\
\text { konsep }\end{array}$ & 7 siswa & $18>x \geq 10$ & $10>x \geq 5$ & $5>x \geq 0$ \\
$\begin{array}{l}\text { Mengklasifikasikan objek } \\
\text { menurut sifat-sifat tertentu }\end{array}$ & 25 siswa & 8 siswa & 1 siswa & 7 siswa \\
$\begin{array}{l}\text { Memberikan contoh dan } \\
\text { bukan contoh }\end{array}$ & 18 siswa & 13 siswa & 3 siswa & 2 siswa \\
$\begin{array}{l}\text { Representasi fisis } \\
\text { matematis }\end{array}$ & - & - & 10 siswa & 26 siswa \\
$\begin{array}{l}\text { Kemampuan } \\
\text { mengaplikasikan konsep } \\
\text { dalam kehidupan sehari- } \\
\text { hari }\end{array}$ & - & 4 siswa & - & 32 siswa \\
\hline
\end{tabular}

Tabel 4.Ketercapaian pada Indikator Penguasaan Konsep Siklus II

\begin{tabular}{lcccc}
\hline \multicolumn{1}{c}{$\begin{array}{c}\text { Indikator Penguasaan } \\
\text { Konsep }\end{array}$} & \multicolumn{3}{c}{ Interval Ketercapaian Skor } \\
\cline { 2 - 5 } $\begin{array}{l}\text { Menyatakan ulang sebuah } \\
\text { konsep }\end{array}$ & 21 siswa & 12 siswa & 3 siswa & - \\
$\begin{array}{l}\text { Mengklasifikasikan objek } \\
\text { menurut sifat-sifat tertentu }\end{array}$ & 21 siswa & 9 siswa & 6 siswa & - \\
$\begin{array}{l}\text { Memberikan contoh dan } \\
\text { bukan contoh }\end{array}$ & 15 siswa & 17 siswa & 4 siswa & - \\
$\begin{array}{l}\text { Representasi fisis } \\
\text { matematis }\end{array}$ & 3 siswa & 8 siswa & 14 siswa & 11 siswa \\
$\begin{array}{l}\text { Kemampuan } \\
\text { mengaplikasikan konsep } \\
\text { dalam kehidupan sehari- } \\
\text { hari }\end{array}$ & - & 16 siswa & 15 siswa & 5 siswa \\
\hline
\end{tabular}


Hasil analisis terhadap ketercapaian penguasaan konsep siswa pada siklus I dan II menunjukkan hasil bahwa model pembelajaran Relating, Experiencing, Applying, Cooperating, Transferring (REACT) dapat meningkatkan penguasaan konsep fisika siswa. Acuan keberhasilan Penelitian Tindakan Kelas ini berdasarkan perbandingan antara target dan hasil ketercapaian terhadap penguasaan konsep fisika siswa (Lefrida, 2013). Target ketercapaian penguasaan konsep ditetapkan berdasarkan hasil dari observasi guru selama proses pembelajaran sebelumnya. Observasi yang dilakukan oleh guru meliputi kegiatan penilaian harian.

Hasil penelitian ini sejalan dengan tujuan model Relating, Experiencing, Applying, Cooperating, Transferring (REACT); yaitu membekali siswa untuk mengaitkan pengetahuan dengan kehidupan sehari-hari maupun konsep materi yang telah dipelajari sebelumnya, sehingga siswa lebih mudah untuk memahami dan menganalisis konsep-konsep yang disampaikan oleh guru. Kemampuan untuk memahami dan mencerna konsep menjadi sebuah landasan awal untuk berpikir dan menyelesaikan masalah. Oleh karena itu, pembelajaran REACT dapat meningkatkan keterampilan pemecahan masalah dan hasil belajar siswa (Mustikaningrum, 2019; Fatmala \& Churiyah, 2016).
Pemberian contoh yang terjadi di kehidupan nyata dapat mempermudah siswa dalam memahami konsep fisika. Hal ini dibuktikan dari ketercapaian yang tinggi pada indikator menyatakan ulang sebuah konsep, mengklasifikasikan objek berdasarkan sifat-sifat tertentu, memberikan contoh dan bukan contoh gerak vertikal. Pada indikator representasi fisis matematis dan kemampuan mengaplikasikan konsep dalam kehidupan sehari-hari; siswa belum memeroleh hasil maksimal karena siswa kurang teliti dalam memformulasikan persamaan gerak vertikal. Kesalahan dalam memformulasikan persamaan menyebabkan siswa tidak dapat menyelesaikan persoalan dengan tepat.

Secara umum, hasil penelitian ini menunjukkan bahwa model pembelajaran REACT dapat meningkatkan pemahaman konsep yang diindikasikan dari hasil berlajar siswa yang meningkat. Hasil ini sesuai dengan penelitian yang dilakukan oleh (Fakhruriza \& Kartika, 2015; Durotulaila, Masykuri, \& Mulyani, 2014; Akmalia, 2019). Pemahaman konsep juga menjadi salah satu indikator bahwa siswa tidak mengalami miskonsepsi, sesuai dengan penelitian Suminten (2015) bahwa pembelajaran REACT secara signifikan dapat mengurangi miskonsepsi siswa. 


\section{KESIMPULAN}

Penerapan model pembelajaran Relating, Experiencing, Applying, Cooperating, Transferring (REACT) dapat meningkatkan penguasaan konsep fisika pada materi gerak vertikal siswa kelas X MIPA 4 SMA $\mathrm{N} 2$ Batang. Peningkatan pemahaman konsep dilihat dari hasil belajar siswa yang mengalami peningkatan dari siklus I ke siklus II. Peningkatan tersebut disebabkan siswa telah terlatih untuk mengaplikasikan konsep dalam kehidupan sehari-hari.

\section{DAFTAR PUSTAKA}

Abdullah, S., \& Shariff, A. 2008. The Effects of Inquiry-Based Computer Simulation With Cooperative Learning on Scientific Thinking and Conceptual Understanding of Gas Laws. Eurasia Journal of Mathematics, Science and Technology Education, 4(4): 387398.

https://doi.org/10.12973/ejm ste $/ 75365$

Akmalia. 2016. Penerapan Model Pembelajaran Relating,

Experiencing, Applying, Cooperating, Transfering (REACT) untuk Meningkatkan Hasil Belajar Geografisiswa SMA Negeri 8 Banda Aceh. Tesis. Banda Aceh: FKIP Universitas Syiah Kuala.

Cahyono, B. A. D., Sutarto, S., \& Mahardika, I. K. 2017. Model
Pembelajaran

(Relating,

REACT

Applying,

Experiencing,

Transfering) Disertai Media

Video Kejadian Fisika

Terhadap Keterampilan Proses

Sains dan Hasil Belajar Siswa dalam Pembelajaran Fisika di SMA. Jurnal Edukasi, 4(3): 20. https://doi.org/10.19184/juka si.v4i3.6155

Cunningham, F. 2005. Obstetri Williams. Jakarta.

Durotulaila, A., Masykuri, M., \& Mulyani, B. 2014. Pengaruh Model Pembelajaran React (Relating, Experiencing, Applying, Cooperating, Transfering) dengan Metode Eksperimen dan Penyelesaian Masalah terhadap Prestasi Belajar Ditinjau dari Kemampuan Analisis Siswa. Jurnal Pendidikan Kimia Universitas Sebelas Maret, 3(4): 66-74.

Effendi, E., \& Pantriani, D. (2020). Penerapan Model

Pembelajaran Generatif Pada Materi Usaha dan Pesawat Sederhana Kelas VIII MTs Nurussalam Sidogede OKU Timur. Physics Education Research Journal, 2(1): 59-68. https://doi.org/10.21580/perj .2020.2.1.4906

Fakhruriza, O., \& Kartika, I. 2015. Keefektifan Model Pembelajaran Relating, Experiencing, Applying, Cooperating, Transferring (REACT) untuk Meningkatkan 
Hasil Belajar Siswa SMP pada Materi Kalor. Jurnal Riset dan Kajian Pendidikan Fisika, 2(2): 54. https://doi.org/10.12928/jrkp f.v2i2.3250

Fariyani, Q. 2019. Model Pembelajaran Kooperatif Jigsaw untuk Meningkatkan Keaktifan dan Hasil Belajar Siswa MTs Kelas VIII. Jurnal Penelitian Pembelajaran Fisika, 10(2): 133-138. https://doi.org/10.26877/jp2f. v10i2.4026

Gardber, H. 1999. Intelligence reframed: Multiple intelligences for the 21st century.

Gowin, N. 1985. Learning how to learn.

GW, Bryan. 2005. Heavy metal contamination in the sea". In $R$. Johnston (Ed.) Effects of pollutans on aquatic organisms.

Ismaya, S., Subiki, S., \& Harijanto, A. 2015. Penerapan Model Pembelajaran Relating, Experiencing, Applying, Cooperating, and Transferring (REACT) terhadap Motivasi dan Hasil Belajar dalam Pembelajaran Fisika di SMA. Jurnal Pembelajaran Fisika Universitas Jember, 4(2).

Jaliah, R., Irawati, R., \& Sujana, A. 2017. Pengaruh Pendekatan Kontekstual Berstrategi Relating, Experiencing, Applying, Cooperating, Transferring (REACT). Jurnal Pena Ilmiah, (20): 1091-1100. Retrieved from http://ejournal.upi.edu/index .php/penailmiah/article/view /11258

Fatmala, K. \& Churiyah, M. 2015. Meningkatkan Hasil Belajar Siswa Melalui Model Pembelajaran Relating, Experiencing, Applying, Cooperating dan Transferring (REACT). Berkala Ilmiah Pendidikan Fisika, 3(2): 122. https://doi.org/10.20527/bipf .v3i2.753

Lailaitul. 2019. Penerapan Strategi REACT untuk Meningkatkan Kemampuan Berpikir Kreatif dan Komunikasi Matematis Siswa SMAN 1 Banda Aceh. Tesis. Banda Aceh: Universitas Syiah Kuala, 2019.

Lefrida, R. 2007. Efektifitas Penerapan Pembelajaran Kontekstual dengan Strategi REACT (Relating, Experiencing, Applying, Cooperating, dan Transferring) untuk Meningkatkan Pemahaman pada materi Logika Fuzzy. Jurnal Pendidikan MIPA FKIP UNTAD, 35-40.

Menteri Pendidikan dan Kebudayan Republik Indonesia. 2013. Kerangka Dasar dan Struktur Kurikulum Sekolah Menengan/Madrasah Aliyah (Standar Penilaian Pendidikan), 1-234.

https://doi.org/10.1017/CBO 9781107415324.004

Mustikaningrum, R. 2019. Penerapan Strategi Pembelajaran Relating, Experiencing, Applying, 
Cooperating, Transferring (REACT) untuk Meningkatkan Keterampilan Pemecahan Masalah Soal Cerita Matematika Peserta Didik Kelas IV Sekolah Dasar, Vol 7, No.

https://doi.org/https://doi.o rg/10.20961/ddi.v7i3.32288

Nasional, U. S. P. 1982. Introduction and Aim of the Study. Acta Pædiatrica, 71, 6-6. https://doi.org/10.1111/j.165 1-2227.1982.tb08455.x Suminten, N. 2015. RelatingExperiencing-ApplyingCooperating-Transferring (REACT) dengan Pendekatan Inkuiri untuk Mengurangi Miskonsepsi Fisika Siswa. Omega: Jurnal Fisika Dan Pendidikan Fisika, 1(2): 6-10.

Wenning, C. J. 2006. A Framework for Teaching The Nature of Science. J. Phys. Tchr. Educ. Online, 3(3): 3-10. 